\title{
Liberalização comercial, déficit em transações correntes e âncora cambial no Brasil nos anos 90*
}

\author{
Fernando Antônio Ribeiro Soares ${ }^{1}$ \\ André Nunes ${ }^{2}$
}

\section{Resumo}

O artigo faz uma análise da importância da liberalização comercial brasileira no início da década de noventa e suas inter-relações com a política de câmbio e com a adoção da âncora cambial na implementação do Plano Real. Observa-se que no período analisado as inter-relações entre a política cambial e comercial ocorrem em duas fases. Em um primeiro momento, a política comercial determinava a política cambial o que causou depreciação da moeda, descrevendo o movimento clássico das taxas de câmbio em um ambiente de liberalização comercial. Na segunda fase, a partir do Plano Real, a política cambial passou a ser empregada como âncora para estabilização do nível de preços, exacerbando o volume de importações e ampliando os efeitos da abertura comercial.

Palavras-chave: Liberalização comercial. Taxa de câmbio. Âncora cambial. Plano Real.

\section{Introdução}

A análise das políticas comerciais de um país deve observar o comportamento das taxas de câmbio, verificando qual a influência desta variável sobre as trocas comerciais de uma economia.

A política cambial e, consequentemente, as taxas de câmbio pouco podem influenciar a proteção fornecida aos setores produtivos domésticos quando estes são

* Recebido em 30.05.2010

Aprovado em 15.06.2010

1 Doutor em Economia (UnB). Diretor do Departamento de Política de Aviação Civil da Secretaria de Aviação Civil do Ministério da Defesa. (fernando.soares@defesa.gov.br).

2 Doutor em Economia (UnB). Professor do UniCEUB. (andre.nunes@uniceub.br). 
analisados separadamente. Na maioria dos casos a ação da taxa de câmbio não irá afetar diferenciadamente as atividades produtivas nacionais. Contudo, temos importantes exceções a serem consideradas: os setores que possuem uma demanda relativamente inelástica por insumos importados e, obviamente, os setores exportadores. Mesmo assim, podemos dizer que a política cambial influencia de forma relativamente linear grande parte dos setores produtivos, agindo indistintamente entre estes por meio de variações nos preços relativos de exportações e importações.

A taxa de câmbio vai ser um indicativo apenas da quantidade global e do sentido das transações comerciais e financeiras, ou seja, caso ela não se encontre em um nível que propicie o equilíbrio externo serão gerados superávits ou déficits comerciais e no próprio balanço de pagamentos. Mas, para fazermos tais considerações precisamos analisar outras variáveis, tais como os índices de inflação doméstica e externa, que conjuntamente irão influenciar a taxa de câmbio real, bem como os níveis de absorção interna e externa. Outro fator de grande relevância na determinação da taxa de câmbio, e assim do comércio exterior, principalmente para o caso brasileiro recente, é o grau de abertura na conta de capitais do balanço de pagamentos e os consequentes fluxos de capitais.

A partir destas definições buscaremos analisar a política cambial brasileira na década de noventa, sendo os principais períodos em questão aquele ocorrido durante a realização da reforma comercial, entre os anos de 1991 e 1993, e aquele após a implementação do Plano Real, entre os anos de 1994 e 1998. Nosso objetivo é entender como a taxa de câmbio se comporta dentro de um contexto de liberalização comercial e, posteriormente, dentro de um contexto de continuidade da liberalização comercial com estabilização econômica, buscando, inclusive, perceber as inter-relações entre a liberalização comercial, o câmbio e a adoção da âncora cambial quando da implementação do Plano Real.

Feitas essas considerações iniciais, segue a estrutura do artigo. A primeira seção encerra-se com esta introdução. Na segunda seção é discutido o relacionamento entre abertura comercial e taxas de câmbio. Na terceira seção, focando o caso brasileiro, é analisada a liberalização comercial implementada nos anos noventa e seu relacionamento com a taxa de câmbio. A quarta seção volta-se para o 
relacionamento da política comercial e cambial durante o Plano Real. Por fim, a última seção é dedicada às considerações finais.

\section{Liberalização comercial e taxas de câmbio}

Em uma economia na qual foram reduzidas as barreiras comerciais, como ocorreu no Brasil, no início da década de noventa, a taxa de câmbio apresentará uma tendência de depreciação caso esta economia se encontre em um regime de taxas de câmbio flexíveis, ou parcialmente flexíveis (flutuação suja).

O mecanismo pelo qual ocorre a elevação da taxa de câmbio durante um processo de abertura comercial é originado na ampliação da demanda de mercadorias importadas, possibilitada pela redução dos preços dessas mercadorias. Em consequência, haverá uma maior demanda por moeda estrangeira para efetivar as compras externas. Com a maior demanda por divisas, tendo esta economia um regime de taxas de câmbio flexíveis e permanecendo tudo mais constante, será provocado um deslocamento do equilíbrio no mercado cambial, que resultará em uma taxa de câmbio mais depreciada.

Alterando a hipótese de cambio flexível e permitindo que as taxas de câmbio sejam fixas ou que possuam uma fixação inicial com posteriores ajustamentos (crawling peg), quando for realizada uma liberalização comercial, haverá uma tendência ao desequilíbrio externo, que, desconsiderando-se novos movimentos de capitais, será financiado pelas reservas internacionais previamente acumuladas. Porém, à medida que as reservas internacionais forem escasseando os desequilíbrios externos tornam-se insustentáveis, sendo inevitável algum ajuste. Pode-se citar, por exemplo, uma desvalorização cambial com reflexos inflacionários ou uma diminuição da absorção doméstica, que traz consigo os custos da desaceleração da atividade econômica. Ou, por outro lado, a reversão no próprio processo de abertura comercial em decorrência da instabilidade macroeconômica. Assim, num contexto de abertura comercial, conjuntamente com a diminuição das barreiras comerciais, as autoridades monetárias deverão ajustar a taxa de câmbio tal que seja alcançado o equilíbrio do balanço de pagamentos. Em outros termos, a realização 
de uma liberalização das relações comerciais requer concomitantemente a depreciação da taxa de câmbio.

Corden (1994) coloca que uma liberalização comercial proporciona, no longo prazo, uma melhoria na eficiência da economia. Em contrapartida, no curto prazo, teremos uma recessão ou, mantida a demanda por bens produzidos domesticamente, um aumento da absorção que causará um déficit comercial. Para evitar o acontecimento de ambos, a recessão ou o desequilíbrio externo, deve-se corretivamente desvalorizar a taxa de câmbio. Caso contrário, seria inevitável algum retrocesso no processo de abertura comercial e o restabelecimento de medidas protecionistas, prejudicando a eficiência da economia e minimizando a credibilidade de futuras políticas comerciais liberalizantes.

Edwards (1995) defende a abertura comercial como um meio de propiciar uma alocação mais eficiente de recursos, acelerar as taxas de crescimento da economia e reduzir o viés anti-exportação gerado pelas barreiras comerciais. O autor, entretanto, também coloca que o comportamento da taxa de câmbio real é vital durante a liberalização comercial, sendo necessário mantê-la depreciada. A explicação, na mesma linha de Corden (1994), é simples: a redução dos preços dos bens importados gera uma tendência natural ao aumento das importações e, no limite, provocará a geração de déficits comerciais. ${ }^{3}$ Para eliminar estes desequilíbrios externos é necessário a expansão das exportações e a limitação do crescimento exponencial das importações, sem contudo retomar as barreiras comerciais, sendo isto possibilitado por uma maior taxa de câmbio real.

Outro fator a ser considerado em uma liberalização comercial é a relação entre proteção e taxa de câmbio. Quando são reduzidas as barreiras comerciais teremos um aumento no valor da taxa de câmbio de equilíbrio. Em outros termos, a taxa de câmbio prevalecente em um ambiente de maior liberdade comercial será superior àquela de um ambiente de controle às importações, como coloca Edwards (1991). Dessa forma, as autoridades monetárias, após uma liberalização comercial,

3 É importante salientar que uma economia que esteja passando por um processo de liberalização comercial apresente, com elevado grau de probabilidade, a existência de uma forte demanda reprimida por bens importados. 
deverão desvalorizar a taxa de câmbio para mantê-la em seu nível de equilíbrio. É importante lembrar que esta política é empregada em regimes de câmbio fixo ou próximo de fixo. Por outro lado, caso o regime seja de câmbio flexível ou aproximadamente flexível o próprio mercado se incumbirá de depreciar a taxa de câmbio, de forma a obter o equilíbrio externo.

\section{A reforma comercial em 1990 e a política cambial}

O mercado cambial brasileiro no início da década de noventa passou por um processo de gradativa liberalização. Foi possibilitado um regime cambial que se aproximava das taxas flutuantes. Porém, as autoridades monetárias continuavam com a primazia de realizarem intervenções no mercado de divisas caso julgassem necessário. Estas intervenções podem ser divididas basicamente em dois grupos: intervenções objetivando a diminuição de movimentos de excessiva apreciação cambial e intervenções visando eliminar as expectativas inflacionárias causadas pelas taxas de câmbio.

Logo no primeiro ano de implementação da reforma comercial, 1991, e principalmente no ano de 1992, as variações da taxa de câmbio corresponderam ao previsto pela teoria quando da realização de uma abertura da economia aos fluxos comerciais, ou seja, houve um processo de depreciação das taxas de câmbio como podemos ver na Tabela 1.

Tabela 1- Evolução da taxa de câmbio real efetiva1 - Base: Fixa IPA-DI, 1989=100

\begin{tabular}{c|c|c|c|c|c|c|c|c|c|c}
\hline & \multicolumn{1}{|c|}{$\mathbf{1 9 8 8}$} & $\mathbf{1 9 8 9}$ & $\mathbf{1 9 9 0}$ & $\mathbf{1 9 9 1}$ & $\mathbf{1 9 9 2}$ & $\mathbf{1 9 9 3}$ & $\mathbf{1 9 9 4}$ & $\mathbf{1 9 9 5}$ & \multicolumn{1}{|c|}{$\mathbf{9 9 6}$} & $\mathbf{1 9 9 7}$ \\
\hline Jan. & 127,1 & 115,8 & 79,0 & 113,1 & 113,8 & 105,3 & 93,9 & 73,5 & 82,4 & 80,3 \\
Fev. & 125,1 & 117,3 & 74,7 & 107,0 & 111,4 & 105,4 & 93,0 & 73,2 & 82,5 & 78,8 \\
Mar. & 126,9 & 116,3 & 66,1 & 99,0 & 113,0 & 103,7 & 91,7 & 78,5 & 83,0 & 77,4 \\
Abr. & 123,9 & 104,5 & 76,9 & 97,1 & 116,8 & 105,4 & 94,1 & 80,6 & 83,2 & 77,2
\end{tabular}




\begin{tabular}{c|c|c|c|c|c|c|c|c|c|c}
\hline & $\mathbf{1 9 8 8}$ & $\mathbf{1 9 8 9}$ & $\mathbf{1 9 9 0}$ & $\mathbf{1 9 9 1}$ & $\mathbf{1 9 9 2}$ & $\mathbf{1 9 9 3}$ & $\mathbf{1 9 9 4}$ & $\mathbf{1 9 9 5}$ & $\mathbf{1 9 9 6}$ & $\mathbf{1 9 9 7}$ \\
\hline Mai. & 125,0 & 101,7 & 77,7 & 99,6 & 116,7 & 103,3 & 98,2 & 81,2 & 82,4 & 78,3 \\
Jun. & 120,7 & 98,4 & 79,1 & 98,3 & 117,7 & 102,2 & 98,9 & 81,9 & 82,0 & 78,4 \\
Jul. & 117,5 & 102,7 & 84,3 & 96,6 & 119,8 & 99,1 & 89,9 & 81,5 & 81,6 & 77,9 \\
Ago. & 117,5 & 95,4 & 83,3 & 95,4 & 115,9 & 98,1 & 83,2 & 79,8 & 82,7 & 77,9 \\
\hline Set. & 114,8 & 88,5 & 80,9 & 97,2 & 112,2 & 97,4 & 79,1 & 82,2 & 82,6 & 78,4 \\
\hline Out. & 116,4 & 88,5 & 92,0 & 104,5 & 110,1 & 97,5 & 76,2 & 85,9 & 82,4 & 79,1 \\
\hline Nov. & 119,4 & 86,1 & 102,0 & 107,5 & 107,4 & 95,9 & 74,1 & 82,5 & 82,9 & 78,9 \\
\hline
\end{tabular}

Fonte: Elaborada pelos autores a partir de dados obtidos junto ao Departamento Econômico do Banco Central do Brasil.

Nota: 1 - Taxa de câmbio real ponderada pela participação nas exportações dos principais parceiros comerciais brasileiros.

No início da reforma comercial, basicamente nos anos de 1991 e 1992, houve a depreciação necessária da taxa de câmbio para manter o equilíbrio externo, permitindo inclusive a geração de superávits comerciais apesar do aumento das importações (Tabela 2). Todavia, a taxa de câmbio não foi o único elemento a permitir a geração desses superávits. Combinada à depreciação cambial houve forte diminuição da atividade econômica. A estagnação do produto propiciou a redução da absorção, o que reduziu as importações. Dessa forma, a variação ascendente da taxa de câmbio conjugada com um menor efeito absorção, mesmo em um ambiente de abertura comercial e de existência de forte demanda reprimida por importações, possibilitaram a geração de superávits comerciais. 
Tabela 2- Comércio exterior brasileiro (1988 - 1997) - US\$ milhões

\begin{tabular}{c|c|c|c}
\hline Ano & Exportações & \multicolumn{1}{c|}{ Importações } & Saldo Comercial \\
\hline 1988 & 33.789 & 14.605 & 19.184 \\
1989 & 34.383 & 18.263 & 16.120 \\
1990 & 31.414 & 20.661 & 10.753 \\
1991 & 31.620 & 21.041 & 10.579 \\
1992 & 35.793 & 20.554 & 15.239 \\
1993 & 38.555 & 25.256 & 13.299 \\
1994 & 43.545 & 33.079 & 10.466 \\
1995 & 46.506 & 49.972 & -3.466 \\
1996 & 47.747 & 53.301 & -5.554 \\
1997 & 52.990 & 61.347 & -8.357 \\
\hline
\end{tabular}

Fonte: Secretaria de Comércio Exterior. Balança comercial brasileira (janeiro/dezembro 1998). Brasília: Ministério do Desenvolvimento, Indústria e Comércio.

Dados os resultados positivos nas contas externas, proporcionados pela depreciação da taxa de câmbio real e pela redução na absorção, foi possível não só a manutenção da reforma comercial, mas o seu aprofundamento nos anos seguintes, 1993 e 1994. A liberalização comercial foi acelerada, havendo a antecipação nas reduções das alíquotas do imposto de importação contidas em seu cronograma.

Porém, a taxa de câmbio real ao final de 1992 e durante o ano de 1993, principalmente a partir do segundo semestre deste último demonstrava outra tendência, dando sinais de apreciação. Os elementos responsáveis por esta modificação na taxa de câmbio real brasileira foram o crescimento dos influxos de capitais, e o consequente excesso de oferta de divisas, e a própria aceleração da inflação. Soma-se a isto a nova orientação da política econômica brasileira, baseada, inicialmente, por menores intervenções no mercado cambial. Em outras palavras, segundo Franco (1995), houve uma flexibilização da taxa de câmbio para baixo. Era o início da âncora cambial e do Plano Real.

\section{A reforma comercial e a política cambial durante o Plano Real}

A partir de 1991 a escassez de recursos externos ocorrida durante a década de oitenta começa a ser revertida. Segundo Franco (1995), a renegociação da dívida 
externa; a redução das taxas de juros norte-americanas, produzindo um elevado diferencial entre as taxas de juros internacionais e domésticas; e o ressurgimento do mercado de bônus, podem ser apontados como os primeiros fatores possibilitadores do retorno dos capitais externos ao Brasil. Calvo et al. (1993) colocam que além da redução das taxas de juros norte-americanas e, naturalmente, das taxas de juros internacionais, a recessão ocorrida nos Estados Unidos e no Japão levaram os capitais externos a procurarem mercados mais rentáveis e, dessa forma, passaram a migrar para os países em desenvolvimento, e, inclusive, para o Brasil.

Edwards (1998) aponta como mais uma causa para o aumento dos influxos de capitais na América Latina, e também no Brasil, a estabilidade da taxa de câmbio, ou mesmo a manutenção desta em níveis mais apreciados. Com esta configuração, a taxa de câmbio produziu um ambiente mais propício à entrada de capitais externos. Complementando este enfoque, Cardoso e Goldfajn (1997) discutem a importância dos planos de estabilização. Com a inflação controlada, haveria a diminuição do risco, pois seria reduzida a possibilidade de se ocorrer novas depreciações cambiais. Assim sendo, são geradas expectativas positivas para os investidores internacionais, favorecendo a ampliação da entrada de capitais externos.

Outros fatores a serem considerados são as reformas institucionais realizadas pelos países latino-americanos e pelo Brasil, apesar destas acontecerem mais tardiamente em nossa economia. Entretanto, mesmo antes do Brasil empreender suas reformas ele foi beneficiado pelo chamado "efeito contágio". O efeito contágio produz influxos de capitais em uma região devido à realização de reformas (comercial, financeira) em um ou mais países desta região. Desta forma, de acordo com Calvo et al. (1993), a realização de reformas em um país gera a expectativa que seus vizinhos venham no futuro a realizar estas reformas, implicando em entradas antecipadas de capitais nestes países vizinhos, ou seja, foi produzida para estes uma externalidade positiva. Porém, como coloca Cardoso e Goldfajn (1997), o reverso também é verdadeiro no efeito contágio: a crise em um país, devido às expectativas, pode se propagar para seus vizinhos, produzindo assim uma externalidade negativa.

As reformas que contribuíram para a criação de um ambiente propício à entrada de capitais foram a já citada estabilização econômica e as tão debatidas 
reformas orientadas para o mercado. Entre estas reformas podem ser citadas, dentre outras, as privatizações, a concessão de serviços públicos, a liberalização comercial e, particularmente, a liberalização dos mercados financeiro e de capitais.

Estes elementos contribuíram para o retorno dos capitais privados externos ao Brasil, mas um fator foi preponderante em permitir a volta destes capitais, bem como para permitir sua diversificação, possibilitando a entrada de um grande volume de capitais de portfólio. Este fator foi a liberalização da conta financeira do balanço de pagamentos. Moreira e Correa (1996) apontam diversas medidas que foram tomadas para desregulamentar os fluxos de capitais: o relaxamento da lei sobre remessa de lucros e dividendos, permitindo o aumento dos investimentos diretos estrangeiros; a autorização para que instituições financeiras sediadas no Brasil mantivessem quantias ilimitadas de moeda estrangeira em seu poder; a possibilidade de ampliação dos depósitos bancários denominados em moeda estrangeira; a autorização para investidores institucionais estrangeiros acessarem ao mercado de ações e de renda fixa brasileiros que gerou aumento expressivo das aplicações de portfólio.

Outro fator que deve ser considerado foi a nova arquitetura das CC5, criada em 1992. De acordo com Franco e Pinho Neto (2004) foi a primeira vez, desde os anos 30, que se estabeleceu um paradigma de conversibilidade em uma área na qual vigoravam controles ex ante de um modo geral, e para o capital estrangeiro em particular. Antes da alteração não poderia haver remessa de recursos para o exterior que não fosse correspondente a ingressos prévios, excetuando-se lucros, juros e royalties. As novas normas produziram uma maior liberdade, elevando o volume de remessa de divisas internacionais.

Todos estes fatores conduziram ao retorno dos capitais externos à economia brasileira durante a década de noventa. Devido aos afluxos de capitais, até o final de 1998, a taxa de câmbio permaneceu apreciada, elemento fundamental na constituição do plano de estabilização econômica. Os capitais externos foram utilizados na estruturação do Plano Real, via ancoragem da taxa de câmbio, o que veio a refletir sobre o volume de comércio. Resumidamente, pode-se apontar que a utilização da âncora cambial como instrumento de estabilização gerou fortes 
impactos sobre o comércio exterior, ampliando os efeitos da reforma comercial pelo lado das importações. Isto, por sua vez, instabilizou parte dos fundamentos macroeconômicos brasileiros, principalmente através do agravamento dos déficits em conta de transações correntes. ${ }^{4}$

Com a liberalização da conta financeira do balanço de pagamentos, além dos diversos fatores internos e externos favoráveis, houve grande entrada de capitais na economia brasileira. Como o câmbio no início do Plano Real se encontrava debaixo de um sistema de taxas aproximadamente flexíveis e, dada esta imensa liquidez externa entrante no País, o mercado cambial foi pressionado pelo excesso de oferta de divisas, redundando na apreciação da moeda. ${ }^{5}$

A apreciação cambial passou a ser um elemento crucial na busca da estabilidade de preços. O primeiro fato a ser relatado, como aponta Franco (1995), é que as taxas de câmbio deixaram de ser administradas, sendo limitadas as intervenções governamentais, e, conjuntamente a esta medida, as taxas de câmbio foram desindexadas, eliminando uma fonte de pressões inflacionárias. Todavia, o principal fator relacionado às taxas de câmbio, que objetivou combater a inflação, foi a criação da âncora cambial.

A âncora cambial é um dos fundamentos de um plano de estabilização baseado nas taxas de câmbio. Neste plano é buscado reduzir os níveis inflacionários através do atrelamento da inflação dos bens comercializáveis à inflação mundial, às expensas da apreciação da moeda e de seus consequentes impactos, como assinala Calvo e Végh (1998). Na economia brasileira, através da âncora cambial somada à liberalização do comércio exterior, foi possibilitado que os preços das mercadorias importadas se tornassem relativamente mais baratos, levando a um aumento do quantum importado. Com a maior facilidade de adquirir bens importados, os

4 Historicamente as balanças de serviços e de rendas são deficitárias no Brasil. Com os desequilíbrios na balança comercial a partir do Plano Real e da ancoragem cambial, a conta de transações correntes tornou-se acentuadamente deficitária.

5 No início do Plano Real houve uma ancoragem natural da taxa de câmbio, dada a apreciação cambial decorrente de movimentos eminentemente de mercados. No ano seguinte, em 1994, em decorrência dos efeitos da crise mexicana sobre o Brasil, o câmbio passa a ser rigidamente administrado - via juros e reservas internacionais - pelas autoridades monetárias. 
setores nacionais produtores de comercializáveis foram forçados a reduzir suas remarcações de preços, bem como viram diminuídas as possibilidades de ampliarem suas margens de lucros. Desta maneira, a partir da competição propiciada pelas mercadorias importadas, houve uma brusca desaceleração nas taxas de crescimento dos índices de preços brasileiros, pelo menos dos bens comercializáveis.

A utilização pelo governo da ancoragem cambial, entretanto, não causou apenas a redução da inflação, mas também trouxe fortes impactos sobre o comércio exterior. Como as taxas de câmbio estavam situadas em níveis muito inferiores aos de equilíbrio, teve origem um vigoroso aumento das importações, aprofundando o processo de abertura comercial. Colocando de outra forma, as importações brasileiras, a partir da implantação do Plano Real, cresceram não apenas em decorrência da eliminação de barreiras tarifárias e não-tarifárias, mas também devido à apreciação cambial. Em contrapartida, as exportações, pelo mesmo motivo, ou seja, a apreciação da taxa de câmbio, tiveram suas taxas de crescimento reduzidas, pois o produto nacional se tornou relativamente mais caro que o produto estrangeiro.

A que pese a importância da liberalização da conta de capital e financeira do balanço de pagamentos para atrair investimentos externos em suas mais variadas formas (direto, empréstimo, portfólio) e, assim, permitir a construção da âncora cambial, fundamental no processo de controle inflacionário, tal propositura contraria o cronograma teórico das reformas econômicas. Em outras palavras, a liberalização comercial, para sua própria continuidade e aprofundamento, não deveria ser realizada simultaneamente com a liberalização dos fluxos cambiais.

\section{Considerações Finais}

Os influxos de capitais foram utilizados para influenciar o comportamento das taxas de câmbio. Essas, por sua vez, foram utilizadas para combater o processo inflacionário. Entretanto, à medida que a taxa de câmbio se apreciou, além de reduzir a inflação, ela também provocou a diminuição dos saldos comerciais. E, a geração de sucessivos déficits comerciais, poderia implicar na não continuidade da reforma comercial como aponta Edwards (1998). 
Sendo assim, observa-se a não convergência na realização simultânea da reforma comercial com a liberalização da conta financeira do balanço de pagamentos, porque, junto à reforma comercial, é necessário uma ação corretiva sobre as taxas de câmbio tal que seja possibilitado a obtenção de um equilíbrio externo compatível com a manutenção da reforma comercial.

No Brasil, conforme pode ser observado na Tabela 1, entre o início da abertura comercial, até julho de 1992, mesmo com a simultaneidade das reformas comercial e da conta de capital e financeira do balanço de pagamentos, houve uma desvalorização cambial. No final do ano de 1992 e, principalmente, a partir do lançamento do Plano Real, a taxa de câmbio começou a se apreciar. Essa apreciação indesejável teve como causa a realização simultânea da reforma comercial e da liberalização da conta capital e financeira, o que colocou em risco a efetiva implementação da abertura comercial. Em 1995, as taxas de câmbio atingiram seus níveis mais baixos, mantendo-se estacionariamente neste patamar para os anos seguintes. Inevitavelmente, foram produzidos sucessivos déficits comerciais, que provocaram uma ação desestabilizadora no balanço de pagamentos.

Dentro de uma crise com essas características, que veio a ocorrer em janeiro de 1999, o governo teria as seguintes opções: reduzir a absorção interna, produzindo uma recessão; desvalorizar a taxa de câmbio e gerar impactos inflacionários; ou retomar o uso de barreiras tarifárias e não-tarifárias. A decisão do governo brasileiro recaiu nas duas primeiras opções.

Em síntese, observa-se que as inter-relações entre a política cambial e comercial nos anos 90 estabeleceram-se em duas fases distintas: antes e depois do Plano Real. Na primeira fase, a política comercial determinava a política cambial; à medida que foram sendo diminuídas as barreiras tarifárias e abolidas as restrições ao comércio, a moeda foi paulatinamente se depreciando, descrevendo o movimento clássico das taxas de câmbio dentro de um ambiente de liberalização comercial. Na segunda fase, a partir do Plano Real, a política cambial passou a ser um dos elementos centrais da política econômica brasileira destinada a estabilizar os níveis gerais de preços. Sua principal influência sobre o comércio foi exacerbar o volume importado, ampliando os efeitos da abertura comercial. Por outro lado, 
as exportações foram prejudicadas pela apreciação cambial, dando origem a desequilíbrios na balança comercial.

\section{Trade liberalization, current account deficit and exchange anchor in Brazil in 90 years.}

\section{Abstract}

The article analyzes the importance of the Brazilian trade liberalization in the early nineties and its interrelations with the exchange rate policy and with the anchor exchange adopted in the implementation of the Real Plan. It is observed that during the period analyzed the interrelations between trade and exchange policy occur in two phases. At first, trade policy determined the exchange rate policy what caused currency depreciation, describing the classical motion of exchange rates in an environment of trade liberalization. In the second phase, from the Real Plan, the exchange rate policy started to be used as an anchor for stabilization the prices level, exacerbating the volume of imports and expanding the effects of trade liberalization.

Keywords: Trade liberalization. Exchange-rate. Exchange-anchor. Real plan.

\section{Referências}

CALVO, Guilhermo A; VÉGH, Carlos A. "Inflation stabilization and BOP crises in developing countries". In: TAYLOR, John; WOODFORD, Michael. Handbook of Macroeconomics. Amsterdam: North Holland, 1998.

CALVO, Guillermo A., LEIDERMAN, Leonardo; REINHART, Carmen M. "Capital inflows and real exchange rate appreciation in Latin America". IMF Staff Papers 40, n. $1,108-151$.

CARDOSO, Eliana; GOLDFAJN, Ilan. Capital flows to Brazil: the endogeneity of capital controls. Working Paper of the International Monetary Fund nº 97/115. Washington, D.C.: International Monetary Fund, 1997. 
CORDEN, W. Max. Economic policy, exchange rates and and the international system. Oxford: Oxford University Press, 1994.

EDWARDS, Sebastian. Real exchange rates, devaluation, and adjustment: exchange rate policy in developing countries. Cambridge, Masssachusetts: MIT Press, 1991.

EDWARDS, Sebastian. Reforma das políticas comercial e industrial na América Latina. In: LARA FRANCO, André; FRANCO, Gustavo H. B. O plano real e outros ensaios. Rio de Janeiro: Francisco Alves, 1995.

EDWARDS, Sebastian; PINHO NETO, Demosthenes M. A desregulamentação da conta e capitais: limitações macroeconômicas e regulatórias. Rio de Janeiro: Departamento de Economia da Pontifícia Universidade Católica do Rio de Janeiro, 2004.

MOREIRA, Maurício Mesquita; CORREA, Paulo Guilherme. Abertura comercial e indústria: o que se pode esperar e o que se vem obtendo. Rio de Janeiro: BNDES, 1996.

REZENDE, André Lara. Políticas para o crescimento: a experiência da América Latina. Fundo Monetário Internacional, 1995.

REZENDE, André Lara. Capital flows, real exchange rates, and capital controls: some Latin American experiences. NBER Working Paper n. 6.800. Cambridge, Massachusetts: National Bureau of Economic Research, 1998. 